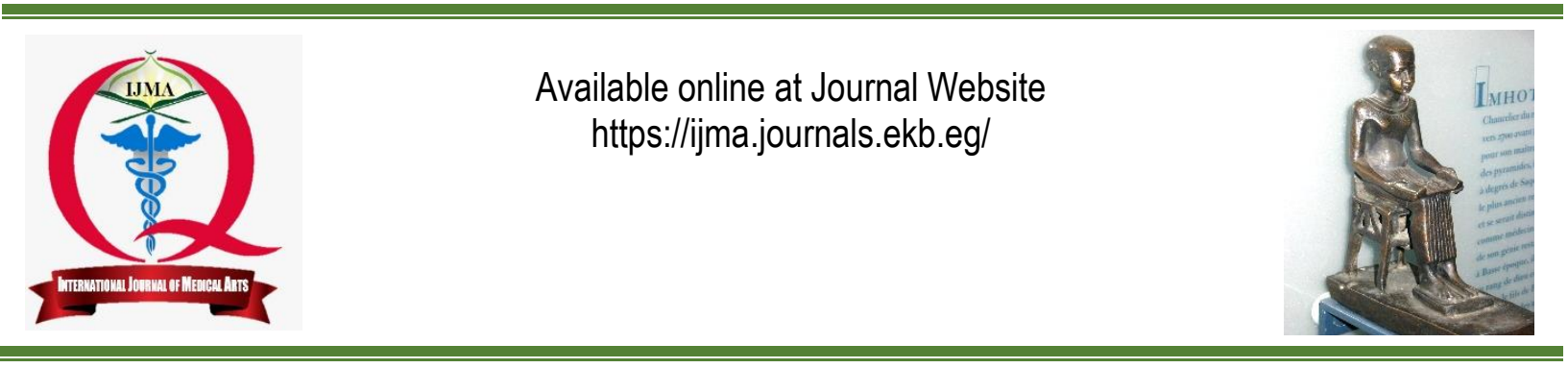

Original article

\title{
Lower Urinary Tract Symptoms Related to Neurological Diseases in Egyptian Patients
}

\author{
Ahmed Yousef Aboelsaad ${ }^{\mathbf{a}}$; Mohie-eldin Tharwat Mohamed ${ }^{\mathbf{b}}$; Mohamed Abdallah Hindawy ${ }^{\mathbf{c}}$
}

Department of Urology, Damietta Faculty of Medicine, Al-Azhar University, Egypt [a]

Department of Neurology, Faculty of Medicine, Al-Azhar University, Egypt [b]

Department of Urology, Faculty of Medicine, Al-Azhar University, Egypt [c]

Corresponding author: Ahmed Yousef Aboelsaad

Email: aboelsaadurology@hotmail.com

Received at: August 7, 2019; Revised At: August 20, 2019.

Accepted at: August 31, 2019; Available online at: August 31, 2019

DOI: 10.21608/ijma.2019.15941.1022

\section{ABSTRACT}

Background: Lower urinary tract symptoms [LUTS] have a marked impact on the quality of life in patients with neurological ailments. They are also linked to a high risk of serious morbidities.

Aim of the work: was to evaluate the LUTS associated with neurological disorders in a sample of Egyptian patients.

Patients and Methods: This study conducted on 104 patients treated in our Neurology and urology clinic at AlAzhar University hospitals from January 2018 to January 2019. Patients divided into several subgroups according to the neurological diagnosis, and the following data were collected: age, sex, irritative symptoms [frequency, urgency, and urge incontinence], obstructive symptoms [straining, slow stream, hesitancy, retention of urine], timing [before or after neurological disease], and finally evolution of symptoms either solved or persistent.

Results: We studied 104 patients; 53 were females and 51 males. LUTS were found in 44 out of 104 patients [42.3\%]. LUTS were more presented in patients with neurovascular, spinal cord and demyelinating disorders. Urinary urge incontinence was the most common symptom [70.4\%]. It was found to be predominant in the neurovascular and demyelinating diseases. In 30 out 44 subjects, the urinary symptoms persist, in 14 out of them the urinary problems were treated.

Conclusions: Storage symptoms are more common, mostly urge urinary incontinence. Neurovascular diseases, spinal cord, and demyelinating diseases are the most common neurological disorders associated with LUTS. A multidisciplinary method should be encouraged for the management of these patients including the whole team of rehabilitation.

Keywords: Lower urinary tract symptoms [LUTS]; Neurological diseases; Urge incontinence; Quality of life; Egyptian.

This is an open access article under the Creative Commons license [CC BY] [https://creativecommons.org/licenses/by/2.0/]

Please cite this article as: Aboelsaad AY, Mohamed MT, Hindawy MA. Lower urinary tract symptoms related to neurological diseases in Egyptian patients. IJMA 2019; 1[2]:98-102. 


\section{INTRODUCTION}

The lower urinary tract composed of the bladder, bladder outlet, and urethra. It has two main functions; the first is urine storage at low pressure, normal sensation and intact continence. The second function is periodic and full intentional evacuation of urine $e^{[1,2]}$.

Integrity of nerve supply for the lower urinary tract [including peripheral nerves, different neural pathways and higher brain centers] are mandatory for normal storage and voiding functions. Thus, any defect in peripheral nerve supply, spinal cord or the brain could lead to abnormal function of the lower urinary tract, in the form of storage, voiding or postmicturition symptoms ${ }^{[3]}$. The dysfunction of lower urinary tract due to neurological illness is a public health problem with marked morbidity and impairment in the quality of life[4].

Patients with LUTS secondary to neurological disorders may have significant complications [e.g., urinary tract infection [UTI], calculi of the upper \& lower urinary tract, sepsis, vesicoureteral reflux [VUR], hydronephrosis and renal failure][5].

Neurologic diseases [e.g., cerebrovascular accident [CVA], neuro-degenerative disease, multiple sclerosis [MS], brain and spinal cord traumatic injury and others] are often associated with LUTS[6].

\section{AIM OF THE WORK}

The aim of this study was to describe the LUTS associated with neurological conditions treated in outpatient neurology clinic of Al- Hussein University Hospital to find most frequent LUTS in these patients; this will improve the medical cooperation between neurologists and urologists, and for a better quality of life in affected patients.

\section{PATIENTS AND METHODS}

The present study included 104 patients treated in outpatient Neurology and urology clinic from January 2018 to January 2019. Patients were classified into subgroups based on the neurological diagnosis: Neurovascular disorders, multiple sclerosis, other demyelinating diseases, neurodegenerative disorders [Parkinsonism and Alzheimer disease], peripheral neuropathy, spinal cord lesions [inflammatory, traumatic, degenerative and neoplastic], motor neuron disease, myasthenia gravis, myopathy, epilepsy, benign intracranial hypertension, CNS tumors and migraine.
Assessment of the status of the urinary system was based on medical examination including history of LUTS, their type, grade, onset, and duration. In addition, other medical conditions were searched for and documented. The history of LUTS specifically including the search for storage dysfunction symptoms [urgency, frequency, and urinary urge incontinence] and voiding dysfunction symptoms [slow stream, intermittency, hesitancy, straining, and feeling of incomplete emptying or retention of urine].

All patients using a bladder catheter were categorized as having voiding dysfunction symptoms.

In the current study, we analyzed prevalence, kind of disorder, the timing of presentation [if before or after the neurological onset] and finally evolution of symptoms either solver or persisting.

Patients who had urinary tract infections excluded from the study because we considered those as confounding factor.

An informed consent was obtained from each patient after full description of the study protocol. In addition, the study was approved by the local research and ethics committee of the faculty of medicine.

\section{RESULTS}

In the present study, a total of 104 consecutive patients included, 53 females and 51 males with age ranged from 18 to 88 years with mean age 44.25 years. As regarding LUTS found in 44 out of 104 cases [42.3\%]; 60 patients [57.7\%] did not show relevant urological symptoms. Characteristics of the sample are illustrated in table 1.

According to neurological diagnosis, $25[24 \%]$ patients had neurovascular disease, 6 [5.8\%] had multiple sclerosis, $6[5.8 \%]$ had other demyelinating diseases, $6 \quad[5.8 \%]$ had neurodegenerative disorders [parkinsonism and Alzheimer disease], 15 [14.4\%] had peripheral neuropathy, spinal cord lesions were observed in 16 [15.3\%], motor neuron disease was found in $3[2.9 \%]$, myasthenia gravis in $5[4.8 \%]$, myopathy in $2[1.9 \%]$, epilepsy in $6[5.8 \%]$ , benign intracranial hypertension in $5[4.8 \%]$, brain tumors in $3[2.9 \%]$ and finally migraine was found in $6[5.8 \%]$. All these findings were illustrated in table 2.

The most common diagnosis was neurovascular disease presented in 25 [24\%] cases. From 44 patients with urological symptoms, 33 
cases reported storage symptoms while 11 cases were affected by voiding symptoms. Specific urinary symptoms are listed in table 3.

The most frequent specific urinary symptom was urge incontinence, reported in 31 [70.4\%] of patients. The urinary symptoms was developed in relation to neurological disorder in 43 out of 44 patients, but was pre-existing in one patient. In 30 out of 44 patients the urinary symptoms persist, in 14 out of them the urinary problem was treated.

From all patients included in this study, 25 patients had diagnosed with a neurovascular disease [24\%]. Between them 18 [72\%] patients presented urinary symptoms $\{17$ [94.4\%] storage and 1 [5.6\%] voiding\}, in 8 [44.4\%] cases the urinary problems were solved and in 10 [55.6\%] cases persist. As regarding patients diagnosed with multiple sclerosis 6 [5.8\%] included in the study, between them 4 [66.7\%] patients presented storage urinary symptoms without voiding symptoms, three of them [75\%] the urinary problem solved and 1 [25\%] LUTS persists. In the present study, 6 [5.8\%] diagnosed by other demyelinating diseases like acute disseminated encephalomyelitis [ADEM] and neuromyelitis optica [NMO], all affected cases presented urinary problems in the form of 5 [83.3\%] storage and $1[16.7 \%]$ voiding, $2[33.3 \%]$ cases the urinary problems were solved and in 4 [66.7\%] the LUTS persists. In the current study, two cases [13.3\%] out of 15 [14.4\%] diagnosed with peripheral neuropathy presented urinary symptoms, one case [50\%] with storage and the other case with voiding symptoms. The only case, the urinary problems occurred before the neurological disease was in this group. In the two cases [100\%] LUTS persists. Spinal cord disorders are important pathologies causing sphincteric disturbances. In our study, 12 [75\%] cases out of 16 cases with spinal cord disorders affected with LUTS. Four patients [33.3\%] were with storage and 8 [66.7\%] were with voiding problems. Retention of urine was observed in 6 [50\%] cases out of them. In all patients, LUTS persists. As regarding detailed diagnosis of patients with spinal cord disease having LUTS; 7 cases diagnosed with transverse myelitis, 3 cases had spinal trauma and 2 cases had spinal cord tumors. Voiding symptoms are an important urinary problem in patients with acute spinal cord disease. Finally, in patients diagnosed with brain tumor 2 out of 3 cases presented storage urinary symptoms, one patient the condition was solved and the another one LUTS currently persists. Data on the prevalence of urinary symptoms with neurological conditions experienced in the present study are reported in table 4.

Table [1]: Characteristics of the sample as regarding age and sex.

\begin{tabular}{|c|c|}
\hline Characteristics & Sample [104] patients \\
\hline $\begin{array}{c}\text { Socio- demographics } \\
\text { Age [Range] } \\
\text { Mean age }\end{array}$ & $\begin{array}{c}18-88 \text { years } \\
44.25 \text { years }\end{array}$ \\
\hline $\begin{array}{ll}\text { Sex } & \\
& \text { Males } \\
& \text { Females }\end{array}$ & $\begin{array}{l}51 \\
53\end{array}$ \\
\hline
\end{tabular}

Table [2]: Diagnosis of neurological patients included in the study.

\begin{tabular}{|l|c|}
\hline \multicolumn{1}{|c|}{ Neurological diagnosis } & Total number [104] patients \\
\hline Neurovascular disease & $25[24 \%]$ \\
\hline Multiple sclerosis & $6[5.8 \%]$ \\
\hline Other demyelinating diseases & $6[5.8 \%]$ \\
\hline Neurodegenerative diseases & $6[5.8 \%]$ \\
\hline Peripheral neuropathy & $15[14.4 \%]$ \\
\hline Spinal cord diseases & $16[15.3 \%]$ \\
\hline Motor neuron disease & $3[2.9 \%]$ \\
\hline Myasthenia gravis & $5[4.8 \%]$ \\
\hline Myopathy & $2[1.9 \%]$ \\
\hline Epilepsy & $6[5.8 \%]$ \\
\hline Benign intracranial hypertension & $5[4.8 \%]$ \\
\hline Brain tumors & $3[2.9 \%]$ \\
\hline Migraine & $6[5.8 \%]$ \\
\hline
\end{tabular}


Aboelsaad et al.

Table [3]: Data about storage and voiding symptoms.

\begin{tabular}{|c|c|}
\hline Urinary symptoms & Neurologic disorders [44 patients] \\
\hline Urge incontinence & $31[70.4 \%]$ \\
\hline Increased frequency [daytime] & $1[2.3 \%]$ \\
\hline Urgency & $1[2.3 \%]$ \\
\hline Retention of urine & $10[22.7 \%]$ \\
\hline Hesitancy & $1[2.3 \%]$ \\
\hline
\end{tabular}

Table [4]: Relation between urinary symptoms with neurological disease.

\begin{tabular}{|l|c|c|c|c|c|c|c|c|}
\hline \multirow{2}{*}{ Diagnosis } & No,\% & \multirow{2}{*}{$\begin{array}{c}\text { Urinary } \\
\text { symptoms }\end{array}$} & \multicolumn{2}{c|}{$\begin{array}{c}\text { Type of } \\
\text { urinary disorder }\end{array}$} & \multicolumn{2}{c|}{ Timing } & \multicolumn{2}{c|}{ Outcome } \\
\cline { 4 - 10 } & & & Storage & Voiding & Pre- & Post-neurologic & Solved & Persistent \\
\hline Neurovascular disease & $25[24 \%]$ & 18 & 17 & 1 & 0 & 18 & 8 & 10 \\
\hline Multiple sclerosis & $6[5.8 \%]$ & 4 & 4 & 0 & 0 & 4 & 3 & 1 \\
\hline Other demyelinating diseases & $6[5.8 \%]$ & 6 & 5 & 1 & 0 & 6 & 2 & 4 \\
\hline Neurodegenerative diseases & $6[5.8 \%]$ & 0 & 0 & 0 & 0 & 0 & 0 & 0 \\
\hline Peripheral neuropathy & $15[14.4 \%]$ & 2 & 1 & 1 & 1 & 1 & 0 & 2 \\
\hline Spinal cord diseases & $16[15.3 \%]$ & 12 & 4 & 8 & 0 & 12 & 0 & 12 \\
\hline Motor neuron disease & $3[2.9 \%]$ & 0 & 0 & 0 & 0 & 0 & 0 & 0 \\
\hline Myasthenia gravis & $5[4.8 \%]$ & 0 & 0 & 0 & 0 & 0 & 0 & 0 \\
\hline Myopathy & $2[1.9 \%]$ & 0 & 0 & 0 & 0 & 0 & 0 & 0 \\
\hline Epilepsy & $6[5.8 \%]$ & 0 & 0 & 0 & 0 & 0 & 0 & 0 \\
\hline Benign intracranial hypertension & $5[4.8 \%]$ & 0 & 0 & 0 & 0 & 0 & 0 & 0 \\
\hline Brain tumors & $3[2.9 \%]$ & 2 & 2 & 0 & 0 & 2 & 1 & 1 \\
\hline Migraine & $6[5.8 \%]$ & 0 & 0 & 0 & 0 & 0 & 0 & 0 \\
\hline
\end{tabular}

\section{DISCUSSION}

LUTS are a common problem and increase with age. The etiologies may multifactorial and include lower urinary tract dysfunction secondary to neurological disorders ${ }^{[7]}$.

In the present study, the prevalence of LUTS was $42.3 \%$. Torelli et al. [8] found that the prevalence of LUTS was only $11 \%$. This difference may be due to exclusion of large cognitive impairment and functional disability in the study of Torelli et al., but in our experience, all patients with neurological disorders were included.

The most frequent specific urinary symptom in this study was urge incontinence, observed in 31 [70.4\%] of all patients. Panicker et al. [9] found that incontinence is a common, yet non-specific symptom of neurogenic lower urinary tract dysfunction and in their study was more common in subjects with suprapontine, infrapontine and suprasacral lesions.

Loss of inhibitory effects at the pons and the sacral centers can lead to detrusor overactivity which reflects on patient symptomatology in the form of the frequency of micturition, urgency and urges incontinence ${ }^{[10,11] .}$
In the study of Torelli et al. [8], the most frequent urinary symptom was urge incontinence in $42.8 \%$.

In our study, urge incontinence was mainly identified in neurovascular disorders, demyelinating diseases, and spinal cord lesions and this result was in agreement with Torelli et al.[8]. The slight prevalence of this kind of urinary disorder in the subgroup of patients with cerebrovascular disease is probably related to the prevalence of neurovascular disease in our study [ $24 \%$ of total diagnosis].

In our study, 18 out of 25 neurovascular patients experienced LUTS [72\%]. In the literature, urge urinary incontinence has been reported in $29 \%$ of cerebral stroke patients at 3 months follow up[12], and in $19 \%$ at 6 months follow up [13].

Based on Gelber ${ }^{[14]}$, the major mechanism responsible for post-stroke urinary incontinence may be the disruption of the neuro-micturition pathways resulting in bladder hyper-reflexia and urge incontinence.

Also, in our series, patients with multiple sclerosis and other demyelinating disorders experienced storage symptoms mostly urge incontinence. A variety of outlines may be reported, but overactivity of detrusor muscle of the bladder 
was recognized in $50 \%$ to $90 \%$ of patients with multiple sclerosis ${ }^{[15]}$.

In our study, urinary voiding problems especially retention of urine were more common than storage symptoms in patients with spinal cord disorders. Also, the most common diagnosis of spinal cord disorders was transverse myelitis in 7 cases, followed by trauma in 3 cases and finally spinal cord tumors in 2 cases. So, the possible explanation for the prevalence of retention of urine in this subgroup is the diagnosis of transverse myelitis [7 cases]. In this acute inflammatory spinal cord disease all sensory, motor and sphincter functions are severely affected and this shock stage accompanied by retention of urine. Panicker et al.[9] found that patients with infrasacral lesions had significantly more retention than patients with suprapontine, infrapontine or suprasacral lesions $[p=0.001]$

In conclusion, LTUS have a negative impact on the quality of life in patients with neurological disorders. Storage symptoms are more common, especially urge incontinence. Neurovascular diseases, spinal cord, and demyelinating disorders are the most common neurological disorders associated with LUTS. A multidisciplinary approach is advocated for therapeutic intervention of those patients involving the rehabilitation team. We proposed a high focus on LUTS in the neurology and neurorehabilitation departments and to stress on the possibility of the first line communication between neurologists and urologists to carry out an earlier and management of LUTS.

\section{Conflict of Interest}

Authors declare that, there was no conflicts of interest.

\section{REFERENCES}

1. Hill WG. Control of urinary drainage and voiding. Clin J Am Soc Nephrol. 2015; 10[3]:480-92. [PMID: 24742475; Doi: $10.2215 /$ CJN.04520413].

2. de Groat WC. Integrative control of the lower urinary tract: preclinical perspective. $\mathrm{Br} J$ Pharmacol. 2006; 147[Suppl 2]:S25-S40. [PMID: 16465182; DOI: 10.1038/sj.bjp.0706604].

3. Leron E, Weintraub AY, Mastrolia SA, Schwarzman P. Overactive Bladder Syndrome: Evaluation and Management. Curr Urol. 2018 Mar; 11[3]:117-125. [PMID: 29692690; DOI: 10.1159/000447205].

4. Stocchetti N, Zanier ER. Chronic impact of traumatic brain injury on outcome and quality of life: a narrative review. Crit Care. 2016 Jun 21; 20[1]:148. [PMID: 27323708; DOI: 10.1186/s13054-016-1318-1].
5. Gormley EA. Urologic complications of the neurogenic bladder. Urol Clin North Am. 2010; 37:601607. [PMID: 20955911; DOI: 10.1016/j.ucl. 2010.07.002].

6. Marcelissen T, Cornu JN, Antunes-Lopes T, Geavlete B, Delongchamps NB, Rashid T, Rieken M, Rahnama'i MS. Management of Idiopathic Overactive Bladder Syndrome: What Is the Optimal Strategy After Failure of Conservative Treatment? Eur Urol Focus. 2018; 4[5]:760-767. [PMID: 29807823; DOI: 10.1016/j.euf.2018.05.004].

7. Wu MP, Su TH. Do lower urinary tract symptoms [LUTS] predispose the individuals to more admissions in Taiwanese women? - A preliminary report. Taiwan J Obstet Gynecol. 2012; 51:402-4. [PMID: 23040925; DOI: 10.1016/j.tjog.2012.07.015]

8. Torelli F, Terragni E, Blanco S, Di Bella N, Grasso M, Bonaiuti D. Lower urinary tract symptoms associated with neurological conditions: Observations on a clinical sample of outpatients neurorehabilitation service. Arch Ital Urol Androl. 2015 Jul 7; 87 [2]:1547. [PMID: 26150035; DOI: 10.4081/aiua.2015.2.154].

9. Panicker JN, MenonL, Anand Kumar A, Sundaram KR, Fowler CJ. Lower urinary tract symptoms following neurological illness may be influenced by multiple factors: Observations from a neurorehabilitation service in a developing country. Neurourology and Urodynamics 2010; 29: 378-81. [PMID: 19475575; DOI: 10.1002/nau.20750].

10. Norris JP, Staskin DR. History, physical examination, and classification of neurogenic voiding dysfunction. Urol Clin North Am 1996; 23: 337-43. [PMID: 8701550].

11. Webster GD. Guralnick ML. The neurourologic evaluation. In: Walsh PC, editor. Campbell's urology, $11^{\text {th }}$ edition. Philadelphia: Saunders; 2002. pp 900 930.

12. Sakakibara R, Hattori T, Yasuda K, Yamanishi. Micturition disturbance after acute hemispheric stroke: analysis of the lesion site by CT and MRI. J Neurol Sci 1996; 137:47-56. [PMID: 9120487; DOI: 10.1016/ 0022-510x [95]00322-s].

13. Nakayama H, Jorgensen HS, Pedersen PM, Raaschou HO, Olsen TS. Prevalence and risk factors of incontinence after Stroke. The Copenhagen Stroke Study. Stroke. 1997; 28:58-62. [PMID: 8996489; DOI: 10.1161/01.str.28.1.58]

14. Gelber DA, Good DC, Laven LJ, Verhulst SJ. Causes of urinary incontinence after acute hemispheric stroke. Stroke. 1993; 24:378-382. [PMID: 8446973; DOI: 10.1161/01.str.24.3.378].

15. Manak A, Lurvink M, Barf HA, Dmochowski RR, Goehring EL Jr, Nguyen-Khoa BA, Jones JK. Epidemiology and healthcare utilization of neurogenic bladder patients in a US clims database. Neurourol Urodyn. 2011; 30: 395- 401. [PMID: 20882676; DOI: 10.1002/nau.21003]. 